\title{
Influence of 2-deoxy-D-glucose and energy substrates on guinea-pig sperm capacitation and acrosome reaction
}

\author{
R. V. Hyne and Kim P. Edwards
}

Reproductive Biology Unit, Royal Women's Hospital and Department of Obstetrics \& Gynaecology, University of Melbourne, Parkville, Victoria 3052, Australia

\begin{abstract}
Summary. When guinea-pig spermatozoa were suspended in a minimal culture medium (MCM-PL), 2-deoxy-D-glucose $(100 \mu \mathrm{M})$ and 2-amino-2-deoxy-D-glucose $(100 \mu \mathrm{M})$ were potent inhibitors of the acrosome reaction without affecting the sperm motility, whereas the $N$-acetyl derivative 2-acetamido-2-deoxy-D-glucose (2 $\mathrm{mm}$ ) had no inhibitory effect. The addition of D-glucose $(2 \mathrm{mM})$ partly inhibited the percentage acrosome reaction of spermatozoa suspended in Medium MCM-PL, but DL- $\alpha-$ glycerophosphate $(2 \mathrm{mM})$ and $m y o$-inositol $(2 \mathrm{mM})$ had no effect. In addition, DL- $\alpha-$ glycerophosphate (2 mM) did not overcome the inhibitory effect of 2-deoxy-D-glucose on the sperm acrosome reaction. The inhibitory action of 2-deoxy-D-glucose (100 $\mu \mathrm{M})$ on the sperm acrosome reaction assessed after a $3-h$ incubation was irreversible and was only completely effective if the sugar was added within $30 \mathrm{~min}$ of the start of incubation. When spermatozoa suspended in Medium MCM-PL were treated with 2deoxy-D-glucose $(100-200 \mu \mathrm{M})$ for an extended incubation up to $6 \mathrm{~h}$, the inhibitory effect of 2-deoxy-D-glucose was partly overcome. Spermatozoa treated with 2-deoxy-Dglucose had significantly reduced concentrations of ATP after incubation for $2 \mathrm{~h}$ in $\mathrm{Ca}^{2+}$-free media, compared with the ATP concentrations of spermatozoa preincubated for $2 \mathrm{~h}$ in $\mathrm{Ca}^{2+}$-free media that supported acrosome reactions. The addition of $\mathrm{Ca}^{2+}(5 \mathrm{mM})$ caused a rapid decrease in ATP concentrations of spermatozoa suspended in Medium MCM-PL, while the addition of the monovalent ionophore monensin (50 $\mu \mathrm{M})$ and $\mathrm{Ca}^{2+}$ stimulated sperm acrosome reactions as well as an additional decline in the sperm ATP concentrations. However, monensin $(50 \mu \mathrm{M})$ in the absence of $\mathrm{Ca}^{2+}$ caused only a slight decline in the sperm ATP concentrations over the $15-\mathrm{min}$ incubation period. The depletion of the sperm ATP concentrations by 2-deoxy-Dglucose may retard completion of the capacitation process and the resultant acrosome reaction.
\end{abstract}

\section{Introduction}

Sperm capacitation and the acrosome reaction are prerequisites for mammalian fertilization in vitro and in vivo. Evidence to date suggests that neither the oviduct, the cells and matrix of the cumulus oophorus, the zona pellucida and other products of ovulation nor the oocyte itself are in any way essential for the onset of a normal acrosome reaction in mammalian spermatozoa (Saling \& Bedford, 1981 ; Bedford, 1983). However, organic factors such as serum albumin and other 'serum factors' are essential additives to chemically defined media that permit spermatozoa to undergo capacitation and fertilization in vitro (mouse: Hoppe \& Whitten, 1974; rat: Niwa \& Chang, 1975; Davis, 1976; guinea-pig: Yanagimachi, 1972; Hyne \& Garbers, 1981; golden hamster: Lui, Cornett \& Meizel, 1977; Mrsny, Waxman \& Meizel, 1979; Bavister, 1981 ; rabbit: Oliphant, 1976; dog: Mahi \& Yanagimachi, 1976, 1978; man: Yanagimachi, Yanagimachi \& Rogers, 1976; Lopata, 
McMaster, McBain \& Johnston, 1978). It has long been proposed that capacitation involves endogenous cellular changes that stem primarily from modifications of the plasmalemma of the spermatozoon (Barros, 1974; O'Rand, 1979; Oliphant \& Singhas, 1979; Bearer \& Friend, 1982), the state of which in turn may regulate a series of biochemical events associated with $\mathrm{Ca}^{2+}$ influx (Hyne \& Garbers, 1979a, b; Hyne, Higginson, Kohlman \& Lopata, 1984).

In addition to the requirement for serum albumin and/or other organic serum factors in sperm capacitating media (Mrsny et al., 1979; Hyne \& Garbers, 1981; Bavister, 1981; Quinn, Stanger \& Whittingham, 1982), all media also contain exogenous energy-producing metabolites for optimal sperm capacitation and fertilization in vitro (Rogers, 1978). Glucose and pyruvate are essential for fertilization of rat eggs (Tsunoda \& Chang, 1975), pyruvate plus lactate in the presence or absence of glucose, as well as glucose alone supported acrosome reactions in guinea-pig spermatozoa (Rogers \& Yanagimachi, 1975), hamster spermatozoa require exogenous glucose and lactate for acrosome reactions in vitro (Dravland \& Meizel, 1981), mouse spermatozoa only require glucose for the sperm acrosome reaction and fertilization (Hoppe, 1976; Fraser \& Quinn, 1981) and human spermatozoa require glucose for optimal penetration of zona-free hamster eggs or human zonae pellucidae (Perreault \& Rogers, 1981; Hoshi, Saito, Suzuki, Hayashi \& Yanagimachi, 1982). Media with an elevated $\mathrm{pH}$ can overcome the requirement for serum factors to support the acrosome reaction in guinea-pig spermatozoa (Hyne \& Garbers, 1981) and possibly dog spermatozoa (Mahi \& Yanagimachi, 1978).

The ability of various minimal culture media having an elevated $\mathrm{pH}$ to support guinea-pig sperm acrosome reactions is related to culture conditions that increase sperm intracellular $\mathrm{Na}^{+}$ concentrations (Hyne et al., 1984). Under these culture conditions, the guinea-pig sperm acrosome reaction is supported by glucose in the presence or absence of pyruvate and lactate, but the appearance of the acrosome reaction is delayed compared with control spermatozoa incubated with only pyruvate and lactate. The retarding effect of glucose on the guinea-pig sperm acrosome reaction appears to be related to its metabolism, since other non-metabolizing sugars such as Lglucose and D-fructose did not have a retarding effect (Rogers \& Yanagimachi, 1975). In this present study, we investigated the effects of various exogenous carbohydrate metabolites on guinea-pig sperm capacitation and the acrosome reaction in vitro, to gain a further understanding of their metabolism during events leading to the acrosome reaction.

\section{Materials and Methods}

Media. The basic sperm capacitating medium (MCM-PL) was a $\mathrm{Ca}^{2+}$-free minimal culture medium (Barros 1974) containing $106 \mathrm{mM}-\mathrm{NaCl}, 1.0 \mathrm{~mm}-\mathrm{MgCl}_{2}, 25.1 \mathrm{~mm}-\mathrm{NaHCO}_{3}, 0.25 \mathrm{~mm}-$ sodium pyruvate, $20 \mathrm{~mm}$-sodium lactate, penicillin (100 units $/ \mathrm{ml})$ and streptomycin sulphate $(50$ $\mu \mathrm{g} / \mathrm{ml}$ ) prepared as described previously (Hyne \& Garbers, 1979b). In some experiments $25 \mathrm{~mm}^{-}$ Tris(hydroxymethyl)methyl-amine (Tris) replaced the $\mathrm{NaHCO}_{3}$ in $\mathrm{Medium} \mathrm{MCM}-\mathrm{PL}$ and the $\mathrm{pH}$ was adjusted to $\mathrm{pH} 8 \cdot 3$ (Tris-PL). In other experiments using the Tris-buffered medium (pH $8 \cdot 3$ ), the substrates pyruvate and lactate were omitted and replaced by 2 mM-glucose or 2 mm-pyruvate. Tyrode's medium (with no albumin) containing pyruvate, lactate and glucose as substrates was prepared as described by Mujica \& Valdes-Ruiz (1983).

The media were stored at $4^{\circ} \mathrm{C}$ and used in experiments within 1 week after preparation.

Sperm preparation and incubation procedure. Adult male guinea-pigs (Dunkin-Hartley or Monash University outbred strain) of $>700 \mathrm{~g}$ weight were anaesthetized with ether and killed by cervical dislocation. The spermatozoa were obtained by back-flushing isolated and lanced epididymidal tails with a solution, containing $150 \mathrm{~mm}-\mathrm{NaCl}$ and $1 \mathrm{~mm}-\mathrm{MgCl}_{2}$, injected with a syringe into the lumen of each vas deferens as described previously (Hyne \& Garbers, 1981). The spermatozoa were washed once by centrifugation $(700 \mathrm{~g}, 10 \mathrm{~min}$ ) and resuspended in $150 \mathrm{~mm}$ $\mathrm{NaCl}-1 \mathrm{~mm}-\mathrm{MgCl}_{2}$ solution. In the general incubation procedure to examine the ability of various 
substrates to inhibit or support the sperm acrosome reaction, samples $(0 \cdot 1 \mathrm{ml})$ of the sperm suspension were added to $0.9 \mathrm{ml}$ Medium MCM-PL in sterile polystyrene tubes with caps (Falcon Plastics No. 2003, Oxnard, CA, U.S.A.) to which aliquants of various sugars or glycolytic substrates had previously been added from concentrated stock solutions. In the experiments with monensin $(0.1 \mathrm{ml})$ samples of the sperm suspension were added to $0.9 \mathrm{ml}$ Medium MCM-PL (previously equilibrated with $5 \% \mathrm{CO}_{2}$ ), in polystyrene tubes with caps, to which monensin, ethanol $(0.005 \mathrm{ml})$ or $\mathrm{Ca}^{2+}$ had previously been added, and were incubated at $25^{\circ} \mathrm{C}$. All incubations were initiated by the addition of spermatozoa $\left(5 \times 10^{6}\right.$ spermatozoa/ $/ \mathrm{ml}$, final concentration $)$ to the assay mixtures. The tubes were placed horizontally on a shaker, rotating at 60 strokes per min, in an incubator at $37^{\circ} \mathrm{C}$ with air as the atmosphere (unless otherwise stated).

Determination of sperm motility and acrosome reaction. At various times during an incubation after the addition of $\mathrm{Ca}^{2+}$, aliquants of the sperm suspension were transferred to a ceramic ring slide (Clay Adams) and mounted under a coverslip. At least 100 spermatozoa were examined to estimate the percentage of motile cells within the entire population of spermatozoa and the percentage of cells without a visible acrosomal cap within the motile sperm population by phaseconstrast microscopy at $\times 160$.

ATP assay. ATP was extracted from the spermatozoa by heat inactivation using a procedure described by Suter, Chow \& Martin (1979). Aliquants $(0.8 \mathrm{ml})$ of the final sperm suspensions were added to stoppered test tubes containing $2.2 \mathrm{ml}$ of pre-heated distilled water in a heating block set at $95^{\circ} \mathrm{C}$. The samples were heated for $10 \mathrm{~min}$, then were transferred to an ice bath and subsequently centrifuged at $2000 \mathrm{~g}$ for $10 \mathrm{~min}$ at $4^{\circ} \mathrm{C}$. The supernatant fluids were then stored at $-80^{\circ} \mathrm{C}$ until assayed.

ATP was assayed by luminescence with purified luciferin-luciferase using a Packard Tri Carb Liquid scintillation spectrometer (model 3320) to measure the luminescence generated at $24^{\circ} \mathrm{C}$ (Stanley \& Williams, 1969; Hammerstedt, 1973). The supplied luciferin-luciferase was reconstituted in a solution containing $1 \%$ bovine serum albumin and $10 \%$ glycerol $(3 \mathrm{mg} / \mathrm{ml})$ and dispensed from a light-shielded bottle. The sperm extract $(0.5 \mathrm{ml})$, water $(0.5 \mathrm{ml})$ and a buffer solution containing $40 \mathrm{~mm}$-glycylglycine $(\mathrm{pH} 7 \cdot 4)$ and $3 \mathrm{~mm}-\mathrm{MgSO}_{4}(1.0 \mathrm{ml})$ were added to clean and previously unused glass scintillation vials. Standard concentrations of ATP $(0-160$ pmol) were prepared in distilled water and prepared for assay using the same procedure as used for the sperm extracts. The reaction was initiated by the addition of $50 \mu$ of the luciferin-luciferase solution and luminescence was recorded using out-of-coincidence counting over a $5 \mathrm{sec}$ period (Stanley \& Williams, 1969).

Chemicals. Luciferin-luciferase (L-0633), 2-deoxy-D-glucose, 2-amino-2-deoxy-D-glucose (Dglucosamine), 2-acetamido-2-deoxy-D-glucose ( $N$-acetyl-D-glucosamine), 2-amino-2-deoxy-D-galactose (D-galactosamine), 3-O-methyl-D-glucopyranose (3-O-methyl-glucose), DL- $\alpha$-glycerophosphate, myo-inositol, sorbitol and D-gluconic acid were obtained from Sigma Chemical Co., St Louis, MO, U.S.A. Stock $10 \mathrm{~mm}$ or $100 \mathrm{~mm}$ solutions of these substrates were prepared in distilled water and were stored at $-20^{\circ} \mathrm{C}$ until use, except 2-amino-2-deoxy-D-glucose which was prepared fresh before each experiment. A stock solution of monensin (10 mM) in ethanol was stored at $-20^{\circ} \mathrm{C}$. All other common chemicals were purchased from BDH (Australia) or Ajax (Australia).

\section{Results}

Effect of various sugars on the sperm acrosome reaction

Guinea-pig spermatozoa incubated in Medium MCM-PL capacitate in the absence of $\mathrm{Ca}^{2+}$ as indicated by their ability to respond to added $\mathrm{Ca}^{2+}$ with acrosome reactions within 10 min after a preincubation period of $>30 \mathrm{~min}$ (Hyne \& Garbers, 1979b, 1981, 1982). After a $2-3 \mathrm{~h}$ incubation in 
this medium, approximately $55-70 \%$ of the motile spermatozoa respond to added $\mathrm{Ca}^{2+}$ with acrosome reactions.

The effect of the presence of various sugars or glycolytic metabolites on the acrosome reaction when spermatozoa were incubated in Medium MCM-PL was investigated (Table 1). After incubation for 2-3 h, D-glucose ( $2 \mathrm{mM})$ slightly inhibited the guinea-pig sperm acrosome reaction in response to the addition of $\mathrm{Ca}^{2+}$ as reported previously (Rogers \& Yanagimachi, 1975; Rogers, Chang \& Yanagimachi, 1979). However, the 2-deoxy-analogues of D-glucose, 2-deoxy-D-glucose (2 $\mathrm{mM}$ ) and 2-amino-2-deoxy-D-glucose (2 mM), completely inhibited acrosome reactions of motile spermatozoa, but the $N$-acetyl derivative 2-acetamido-2-deoxy-D-glucose ( $2 \mathrm{~mm}$ ) had no inhibitory effect (Table 1). The substrates DL- $\alpha$-glycerophosphate ( $2 \mathrm{~mm}$ ) and sorbitol ( $2 \mathrm{~mm})$ which have been reported to be metabolized by guinea-pig spermatozoa (Frenkel, Peterson \& Freund, 1975) did not inhibit the sperm acrosome reaction and DL- $\alpha$-glycerophosphate $(2 \mathrm{mM})$ did not overcome the inhibitory effect of 2-deoxy-D-glucose. Similarly, the addition of myo-inositol ( $2 \mathrm{mM}$ ) or D-gluconic acid ( $2 \mathrm{mM}$ ) did not inhibit the acrosome reactions of motile spermatozoa incubated in Medium MCM-PL (Table 1). All treatments showed a similar percentage of motile spermatozoa over the $2-3 \mathrm{~h}$ incubation period.

Table 1. The effects of various sugars on the acrosome reaction of guinea-pig spermatozoa incubated in Medium MCM-PL

\begin{tabular}{lc}
\hline \multicolumn{1}{c}{ Treatment } & $\%$ Acrosome reaction \\
\hline Control & $64 \pm 3$ \\
D-Glucose & $46 \pm 17$ \\
2-Deoxyglucose & $<1$ \\
2-Glucosamine & $<1$ \\
N-Acetyl-2-glucosamine & $70 \pm 16$ \\
2-Amino-2-deoxy-D-galactose & $31 \pm 15$ \\
3-O-Methyl-D-glucose & $74 \pm 3$ \\
DL- $\alpha$-Glycerophosphate & $56 \pm 5$ \\
DL- $\alpha$-Glycerophosphate + 2-deoxyglucose & $<1$ \\
$M y o$-inositol & $62 \pm 3$ \\
Myo-inositol + 2-deoxyglucose & $<1$ \\
Sorbitol & $59 \pm 4$ \\
D-Gluconic acid & $67 \pm 2$ \\
\hline
\end{tabular}

Spermatozoa were incubated in Medium MCM-PL in the presence of the various substrates indicated $(2 \mathrm{mM})$ for $2-3 \mathrm{~h} . \mathrm{Ca}^{2}+(5 \mathrm{mM}$, final conc.) was added to the sperm suspensions for the final $10 \mathrm{~min}$ of the incubation. The percentage of motile spermatozoa without acrosomal caps was then assessed. The percentages of motile spermatozoa were not different for any of the treatments and varied from 50 to $65 \%$. Values shown are the mean \pm s.e.m. for 3 animals.

\section{Factors influencing the inhibitory action of 2-deoxy-D-glucose}

The effect of various concentrations of 2-deoxy-D-glucose and 2-amino-2-deoxy-D-glucose (glucosamine) on the $\mathrm{Ca}^{2+}$-induced acrosome reaction was assessed on spermatozoa incubated for $3 \mathrm{~h}$ in Medium MCM-PL (Text-fig. 1). 2-Deoxy-D-glucose was a more effective inhibitor of the percentage of motile spermatozoa undergoing acrosome reactions than glucosamine, with concentrations of 2-deoxy-D-glucose $\geqslant 100 \mu \mathrm{M}$ completely inhibiting the occurrence of the sperm acrosome reaction in response to the addition of $5 \mathrm{mM}^{-\mathrm{Ca}^{2+}}$. The inhibitory action of 2-deoxy-Dglucose $(100 \mu \mathrm{M})$ on the acrosome reaction assessed at $3 \mathrm{~h}$ was only completely effective if the 2deoxy-D-glucose was added to the spermatozoa suspended in Medium MCM-PL within 30 min of the start of the incubation. Spermatozoa treated with 2-deoxy-D-glucose $(100 \mu \mathrm{M})$ after $0 \cdot 5,1,1 \cdot 5,2$ 
or $2.5 \mathrm{~h}$ and then incubated for a total of $3 \mathrm{~h}$ gave $2 \pm 2,17 \pm 8,29 \pm 17,28 \pm 12$ and $56 \pm 6 \%(n=$ 4) acrosome reactions. Thus, 2-deoxy-D-glucose $(100 \mu \mathrm{M})$ added after $30 \mathrm{~min}$ did not prevent the motile spermatozoa from undergoing acrosome reactions at $3 \mathrm{~h}$ and did not inhibit the percentage of motile spermatozoa ( $50-60 \%$ after $3 \mathrm{~h}$ in all treatments), but the acrosome-reacted spermatozoa under these conditions did not show the vigorous motility change normally associated with an acrosome reaction (Yanagimachi \& Usui, 1974). When guinea-pig spermatozoa incubated in Medium MCM-PL containing 2-deoxy-D-glucose $(100 \mu \mathrm{M})$ for $135 \mathrm{~min}$ were washed twice by centrifugation and resuspended in Medium MCM-PL before the addition of $5 \mathrm{mM}^{-} \mathrm{Ca}^{2+}$, the percentage of acrosome reactions was $<10 \%$ compared with a control not treated with 2-deoxy-Dglucose which gave $75 \%$ acrosome reactions. In contrast, when spermatozoa were treated with low concentrations of 2-deoxy-D-glucose $(100$ or $200 \mu \mathrm{M})$ for an extended incubation period, before the addition of $\mathrm{Ca}^{2}+(5 \mathrm{mM})$, the inhibitory effect of 2-deoxy-D-glucose was overcome (Text-fig. 2). The addition of 8-Br-ATP (5 mM) or 8-Br-cAMP (5 mM) to spermatozoa suspended in Medium MCMPL containing 2-deoxy-D-glucose $(150 \mu \mathrm{M})$ did not overcome the inhibitory effect of 2-deoxy-Dglucose in preventing the acrosome reaction (data not shown). The addition of $\mathrm{Na}_{2} \mathrm{HPO}_{4}(1 \mathrm{~mm})$ alone or in treatments containing the 8-bromo-adenosine nucleotides did not prevent 2-deoxy-Dglucose from inhibiting the sperm acrosome reaction.

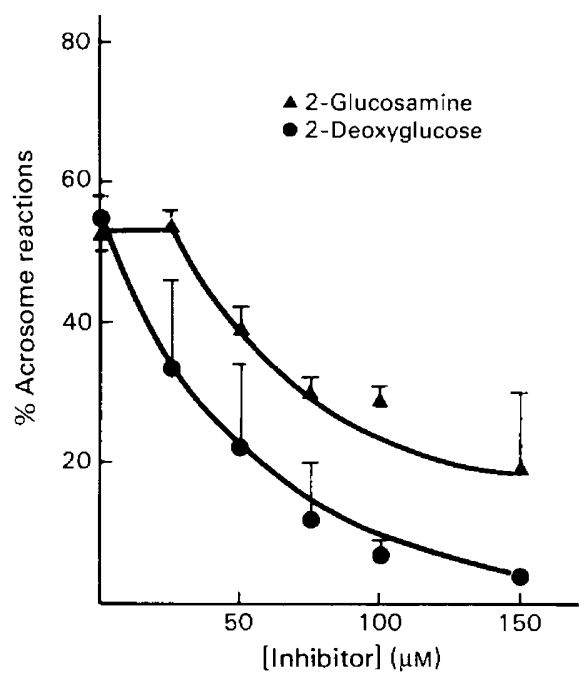

Text-fig. 1. The effect of different concentrations of 2-deoxy-D-glucose or 2-glucosamine on the guinea-pig sperm acrosome reaction. Spermatozoa suspended in Medium MCM-PL were incubated with the inhibitor for $3 \mathrm{~h} ; \mathrm{Ca}^{2+}(5 \mathrm{mM}$, final conc.) was added for the final $10 \mathrm{~min}$ of the incubation and the percentage of acrosome reactions was then assessed. The percentage of motile spermatozoa was not different for any of the treatments and varied from 50 to $60 \%$. Values are the mean \pm s.e.m. for 3 observations.

\section{Sperm ATP content and acrosome reactions in the presence of various substrates}

Spermatozoa were incubated in Tris-buffered media ( $\mathrm{pH} 8 \cdot 3$ ) containing glucose ( $2 \mathrm{mM}$ ) or pyruvate $(2 \mathrm{mM})$ or both pyruvate $(0.25 \mathrm{mM})$ and lactate $(20 \mathrm{~mm})$ as substrates and Medium MCMPL, with 2-deoxy-D-glucose $(2 \mathrm{mM})$ included in some treatments. The ATP content of the spermatozoa was measured $2 \mathrm{~min}$ and $2 \mathrm{~h}$ after the start of incubation and the percentage of motile spermatozoa and percentage acrosome reaction were assessed after $2 \mathrm{~h}$ in response to the addition of $\mathrm{Ca}^{2+}$. Acrosome reactions were only observed with spermatozoa incubated in media containing 


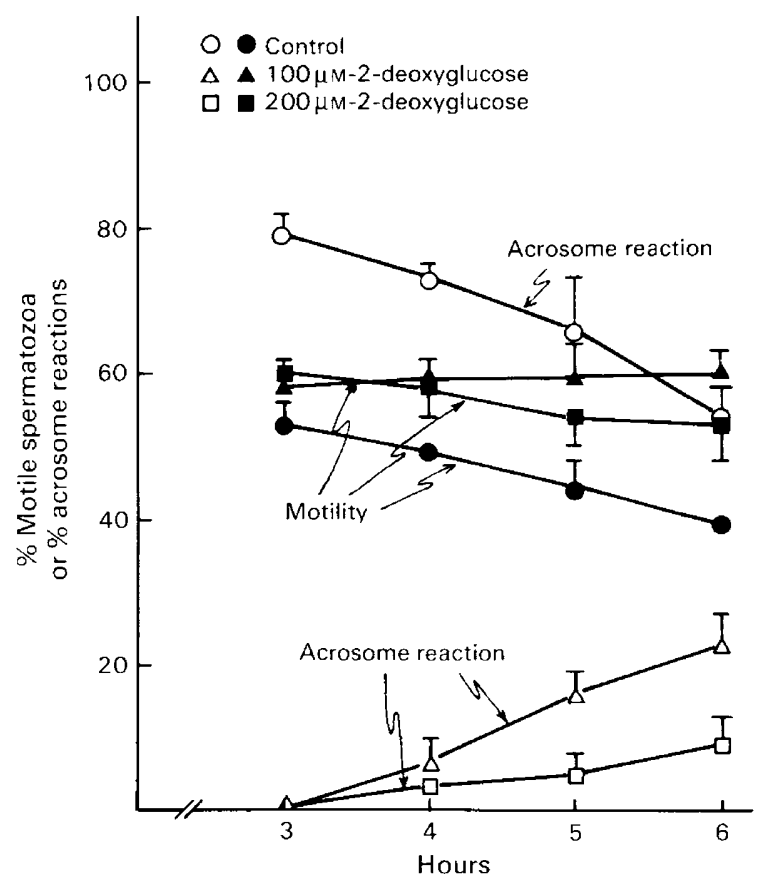

Text-fig. 2. Effect of incubation time on the inhibitory action of 2-deoxy-D-glucose on the guinea-pig sperm acrosome reaction. Spermatozoa were incubated for the various times indicated in Medium MCM-PL alone $(O$, $)$, Medium MCM-PL with $100 \mu \mathrm{M}$-2-deoxy-Dglucose $(\triangle, \boldsymbol{\Delta})$ or Medium MCM-PL with $200 \mu \mathrm{M}$-2-deoxy-D-glucose $(\square, \boldsymbol{\square}) . \mathrm{Ca}^{2+}(5 \mathrm{~mm}$, final conc.) was added to the sperm suspensions $10 \mathrm{~min}$ before determination of the percentage of motile spermatozoa $(\boldsymbol{\Lambda}, \boldsymbol{\Delta}, \boldsymbol{\square})$ or percentage of acrosome reactions $(O, \Delta, \square)$. Each value is the mean \pm s.e.m. for 3 animals.

Table 2. The effects of various substrates on the ATP content and acrosome reaction of guinea-pig spermatozoa incubated in bicarbonate- and Tris-buffered media

\begin{tabular}{|c|c|c|c|c|}
\hline \multirow[b]{2}{*}{ Treatment } & \multicolumn{2}{|c|}{ ATP $\left(\mathrm{nmol} / 10^{8}\right.$ spermatozoa $)$} & \multirow{2}{*}{$\begin{array}{l}\% \text { Acrosome } \\
\text { reaction }\end{array}$} & \multirow[b]{2}{*}{$\%$ Motility } \\
\hline & $2 \min$ & $120 \mathrm{~min}$ & & \\
\hline MCM-PL & $23 \cdot 5+1 \cdot 8$ & $22 \cdot 7+7 \cdot 4$ & $63+10$ & $57+3$ \\
\hline MCM-PL + 2 mM-2-deoxy-glucose & $17 \cdot 0 \pm 5.3$ & $2 \cdot 4 \pm 0.5$ & $\overline{<1}$ & $63 \pm 2$ \\
\hline Tris-PL & $19.0 \pm 1.4$ & $14.5+3.4$ & $38+11$ & $58+1$ \\
\hline Tris-PL $+2 \mathrm{mM}-2$-deoxy-glucose & $13 \cdot 0+2 \cdot 5$ & $1 \cdot 3+0 \cdot 1$ & $<1$ & $58+4$ \\
\hline Tris +2 mM-pyruvate & $24.7 \pm 0.8$ & $4 \cdot 1 \pm 1 \cdot 0$ & $<1$ & $60 \pm 6$ \\
\hline Tris + 2 mm-glucose & $19 \cdot 1 \pm 3 \cdot 1$ & $7 \cdot 8 \pm 2.6$ & $<1$ & $59 \pm 3$ \\
\hline
\end{tabular}

Spermatozoa were incubated with the substrates indicated for $2 \mathrm{~h}$ and at 2 and $120 \mathrm{~min}$ aliquants of the sperm suspension were removed to determine the sperm ATP concentration. After $2 \mathrm{~h}, \mathrm{Ca}^{2+}(5 \mathrm{~mm}$, final conc.) was added and $10 \mathrm{~min}$ later the percentage motility and the percentage of motile spermatozoa without acrosomal caps were assessed. Values shown are the mean \pm s.e.m. for 3 animals.

both pyruvate $(0.25 \mathrm{~mm})$ and lactate $(20 \mathrm{~mm})$ as substrates and with no added 2-deoxy-D-glucose (Table 2). These spermatozoa also had maintained high ATP concentrations after incubation for $2 \mathrm{~h}$ compared with spermatozoa incubated in media containing 2-deoxy-D-glucose ( $2 \mathrm{mM})$, glucose ( $2 \mathrm{~mm}$ ) alone or pyruvate ( $2 \mathrm{~mm}$ ) alone. The addition of 2-deoxy-D-glucose ( $2 \mathrm{~mm})$ to spermatozoa incubated with pyruvate and lactate caused a significant decrease in the sperm ATP concentrations 
after incubation for $2 \mathrm{~h}\left(2.4 \pm 0.5 \mathrm{nmol} / 10^{8}\right.$ cells $)$ and the decline in the ATP concentrations appeared to be rapid as they were reduced after incubation for $2 \mathrm{~min}$ (Table 2). Prolonged incubation of spermatozoa treated with 2-deoxy-D-glucose $(100 \mu \mathrm{M})$ in Medium MCM-PL produced a further reduction in the sperm ATP concentrations $\left(0.9 \pm 0.5 \mathrm{nmol} / 10^{8}\right.$ cells, $n=4$, after $5 \mathrm{~h}$ and $0.7 \pm 0.1 \mathrm{nmol} \mathrm{ATP} / 10^{8}$ cells, $n=4$, after $6 \mathrm{~h}$ ).

In the presence of D-glucose as the only substrate, guinea-pig spermatozoa only undergo acrosome reactions after an extended incubation period (Rogers \& Yanagimachi, 1975; Hyne \& Garbers, 1981). Acrosome reactions occurred in Tris-buffered medium with pyruvate and lactate as substrates, but were reduced compared with values in bicarbonate-buffered medium (Table 2).

\section{Sperm ATP content during monensin-stimulated acrosome reactions}

Spermatozoa collected in $\mathrm{Ca}^{2+}$-free media composed of $150 \mathrm{~mm}-\mathrm{NaCl}$ and $1 \mathrm{mM}-\mathrm{MgCl}_{2}$ or 300 mM-sucrose and $1 \mathrm{mM}-\mathrm{MgCl}_{2}$ were transferred to Medium MCM-PL which was previously equilibrated with $5 \% \mathrm{CO}_{2}$. In the presence of $\mathrm{Ca}^{2+}(5 \mathrm{~mm})$ and monensin $(50 \mu \mathrm{M})$ the motile spermatozoa showed rapid acrosome reactions $(20-40 \%)$ within 5-10 min (Text-fig. 3 ) as described previously (Hyne et al., 1984; Hyne, 1984). Under these conditions, the sperm ATP concentration declined rapidly during the first 5 min of incubation and then stabilized at approximately $10 \%$ of the initial value. In comparison, in a treatment containing $0.5 \%$ ethanol and $\mathrm{Ca}^{2+}(5 \mathrm{mM})$, the sperm ATP concentration also initially declined rapidly within 5 min of the start of incubation, but the sperm ATP content then stabilized at a concentration 2-3-fold above the monensin-treated spermatozoa. Spermatozoa treated with monensin in the absence of added $\mathrm{Ca}^{2+}$ did not show a rapid decline in their ATP concentration, but rather a more gradual decrease in ATP concentration over the incubation period (Text-fig. 3). The spermatozoa in all treatments maintained good motility $(60-70 \%)$ over the incubation period, but acrosome reactions were only observed in the

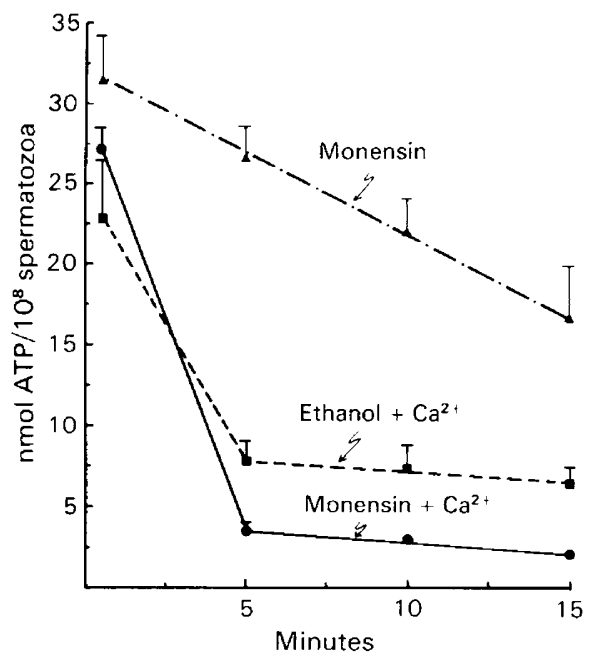

Text-fig. 3. Guinea-pig sperm ATP concentrations in the presence of monensin and extracellular $\mathrm{Ca}^{2+}$. Spermatozoa were suspended at $25^{\circ} \mathrm{C}$ in Medium MCM-PL (pH 7.5) with $0.5 \%$ ethanol and $5 \mathrm{mM}-\mathrm{Ca}^{2+}(\boldsymbol{\square})$, Medium MCM-PL (pH 7.5) with $50 \mu \mathrm{M}$-monensin $(\boldsymbol{\Delta})$ or Medium MCM-PL ( $\mathrm{pH} 7 \cdot 5$ ) with $50 \mu \mathrm{M}$-monensin and $5 \mathrm{mM}^{-\mathrm{Ca}^{2+}}(\mathbf{O})$. At the various times indicated aliquants of the sperm suspension were removed to determine the sperm ATP concentration. The spermatozoa in all treatments maintained $60-75 \%$ motility over the incubation period. Acrosome reactions $(20-40 \%)$ were only observed in the treatment containing $50 \mu \mathrm{M}$-monensin and $5 \mathrm{mM}-\mathrm{Ca}^{2+}$ after $5 \mathrm{~min}$ incubation time. Values are the mean \pm s.e.m. of 3 animals. 
presence of both $\mathrm{Ca}^{2+}$ and monensin. If the spermatozoa were resuspended in media buffered with $\mathrm{HCO}_{3}{ }^{-} / \mathrm{CO}_{2}(\mathrm{pH} 7 \cdot 5)$ similar in composition to Medium MCM-PL except that the substrates pyruvate and lactate were omitted and $5 \mathrm{~mm}$-glucose or no substrates were utilized, then the addition of monensin $(50 \mu \mathrm{M})$ inhibited the sperm motility within $10 \mathrm{~min}$ in the presence of $5 \mathrm{~mm}-$ $\mathrm{Ca}^{2+}$ (data not shown).

\section{Discussion}

These studies confirm previous observations that the metabolic state of the spermatozoon can influence and regulate the process of capacitation and the acrosome reaction (Rogers \& Yanagimachi, 1975; Hoppe, 1976; Rogers, Ueno \& Yanagimachi, 1977; Fraser \& Quinn, 1981). Culture conditions that maintain high ATP concentrations in guinea-pig spermatozoa during incubation in vitro also support a short capacitation period and a rapid onset of the acrosome reaction. Media containing both pyruvate and lactate as substrates maintained higher concentrations of ATP in guinea-pig spermatozoa and supported a more rapid onset of acrosome reactions than did media containing pyruvate alone or glucose (Rogers \& Yanagimachi, 1975; Hyne \& Garbers, 1981). The 2-deoxy analogues of gluose, 2-deoxy-D-glucose and 2-amino-Dglucose, are very potent inhibitors of the acrosome reaction of guinea-pig spermatozoa when incubated with pyruvate and lactate as substrates, whereas the $\mathrm{N}$-acylated derivative 2-acetamido2-deoxy-D-glucose was ineffective. Both 2-deoxy-D-glucose and 2-amino-D-glucose are phosphorylated by hexokinase, while the $N$-acylated derivative is not phosphorylated (Webb, 1966; Hiipakka \& Hammerstedt, 1978), suggesting that the phosphorylation of these sugars, and the resultant accumulation of the stable 6-phosphate metabolites, is responsible for their irreversible inhibitory action. Possible reasons for the potent inhibitory effect of 2-deoxy-D-glucose might include inhibition of phosphoglucose isomerase or other glycolytic enzymes, as well as depletion of the ATP concentrations. The addition of exogenous DL- $\alpha$-glycerophosphate, which is metabolized by guinea-pig spermatozoa (Frenkel et al., 1975), did not overcome the inhibitory action of 2-deoxy-Dglucose, suggesting that the inhibition produced by 2-deoxy-D-glucose was perhaps not due to depletion of some of the endogenous glycolytic metabolites, but to the diversion of intracellular phosphate to the stable 2-deoxy-D-glucose-6-phosphate and depletion of the cellular ATP concentrations.

2-Deoxy-D-glucose was only completely effective in preventing acrosome reactions if the sugar was added to the sperm suspension. within $30 \mathrm{~min}$ of the start of incubation. The addition of 2deoxy-D-glucose also appeared to decrease the sperm ATP concentrations rapidly. These data suggest that there may be an essential requirement for an ATP-dependent reaction, or phosphorylation of an unknown receptor, to be completed during capacitation before spermatozoa undergo the acrosome reaction. Prolonged incubation of spermatozoa treated with 2-deoxy-Dglucose partly overcame the block to the acrosome reaction, despite the reduced ATP concentrations.

The mechanisms involved in the sperm capacitation process may have analogies with the maturation and ageing of mammalian erythrocytes, whereby energy depletion retards the maturation-associated loss of membrane transport functions during reticulocyte maturation (Weigensberg \& Blostein, 1983). The present study demonstrates that culture conditions that support a short capacitation period and a rapid onset of acrosome reactions also maintain elevated guinea-pig sperm ATP concentrations. These culture conditions also support a rapid $\mathrm{Ca}^{2+}$ and $\mathrm{HCO}_{3}{ }^{-}$-dependent rise in cyclic AMP concentrations (Hyne \& Garbers, 1979b; Garbers, Tubb \& Hyne, 1982) and lead to elevated sperm intracellular $\mathrm{Na}^{+}$concentrations (Hyne et al., 1984). The induction of rapid acrosome reactions by the $\mathrm{Na}^{+}$-ionophore monensin is also dependent on extracellular $\mathrm{Na}^{+}$and $\mathrm{Ca}^{2+}$ at an optimal $\mathrm{HCO}_{3}{ }^{-}$concentration (Hyne, 1984) and in addition require the oxidative substrates pyruvate and lactate that maintain high guinea-pig sperm ATP concentrations. 
The $\mathrm{Ca}^{2+}$-dependent depletion of guinea-pig sperm ATP concentrations observed in this study may explain, in part, why an initial preincubation of guinea-pig spermatozoa in $\mathrm{Ca}^{2+}$-free media supports a shorter capacitation period and more rapid onset of acrosome reactions (Hyne \& Garbers, 1979b).

These observations contrast with those obtained by Santos-Sacchi \& Gordon (1982) who induced synchronous acrosome reactions in guinea-pig spermatozoa by initially preincubating the spermatozoa in substrate-free medium to deplete the sperm ATP concentrations and then stimulating acrosome reactions by the addition of pyruvate. Glucose did not substitute for pyruvate in the procedure and the authors showed that the addition of pyruvate was essential to enable the ATP-depleted spermatozoa to resynthesize ATP. Maximal acrosome reactions occurred after 60 min of the addition of the pyruvate, suggesting that the ATP was necessary for the membrane fusion reaction. Santos-Sacchi \& Gordon (1982) suggested that the initial preincubation of the spermatozoa in the substrate-free medium to deplete ATP concentrations led to a rapid capacitation due to inactivation of a $\mathrm{Ca}^{2+}$-dependent ATPase expulsion mechanism for $\mathrm{Ca}^{2+}$, thereby permitting $\mathrm{Ca}^{2+}$ influx. An alternative explanation is that the ATP-depletion of the spermatozoa would lead to elevated intracellular $\mathrm{Na}^{+}$concentrations, a rate-determining event previously associated with treatments that stimulate synchronous guinea-pig sperm acrosome reactions (Hyne et al., 1984).

A novel procedure for inducing guinea-pig sperm acrosome reactions has been described by Mujica \& Valdes-Ruiz (1983): the spermatozoa were preincubated in Tyrode's medium containing glucose as substrate and then transferred to a minimal culture medium containing pyruvate and lactate. The authors concluded that guinea-pig sperm capacitation occurred within a short time after incubation in Tyrode's medium and that capacitation was not delayed by glucose, but that the acrosome reaction was arrested by a glucose metabolite. In addition, Mujica \& Valdes-Ruiz (1983) found that the capacitation of the spermatozoa incubated in Tyrode's medium was not $\mathrm{pH}$ dependent, in contrast to the results of Hyne \& Garbers (1981). The occurrence of acrosome reactions in the transferred spermatozoa was determined quantitatively by fixing the sperm suspension with formaldehyde and the results compared with spermatozoa incubated continuously in minimal culture medium containing pyruvate and lactate, but which were not carried through the centrifugation step (Mujica \& Valdes-Ruiz, 1983). However, when guinea-pig spermatozoa were treated by this procedure and the occurrence of acrosome reactions quantitatively assessed by observation of wet mount aliquants of motile spermatozoa, we did not observe a significant percentage of acrosome reactions in the motile sperm population. The reason for this discrepancy is not readily apparent, but one possible cause may be the centrifugation procedure inducing a $\mathrm{Ca}^{2+}$ dependent acrosome-loss in live but immotile spermatozoa, compared with the control treatments that were not centrifuged.

The reason high ATP concentrations are required for rapid sperm capacitation is unknown, but ATP or cyclic AMP-dependent phosphorylation of membrane lipid or protein in the acrosomal region at the site of membrane fusion may be involved. Attempts to identify phosphorylated sites in spermatozoa (Brandt \& Hoskins, 1980; Bearer \& Friend, 1982) have had only limited success because intact spermatozoa do not equilibrate extracellular and intracellular Pi (Babcock, First \& Lardy, 1975). This explains why added phosphate did not overcome the inhibitory effect of 2deoxy-D-glucose. It has been suggested that polyphosphoinositide may be responsible for $\mathrm{Ca}^{2+}$ sequestration in the guinea-pig acrosome (Friend, 1982; Bearer \& Friend, 1982) and membrane fusion of myoblasts (Wakelam, 1983). Cyclic AMP-dependent protein kinase has been reported to stimulate indirectly the formation of polyphosphoinositides in the plasma membranes of different blood cells (Enyedi, Farago, Sarkadi, Szasz \& Gardos, 1983). Alternatively, membrane phosphorylation may regulate the kinetic properties of the $\mathrm{Na}^{+} / \mathrm{Ca}^{2+}$ exchanger (Reeves \& Sutko, 1983; Rufo, Schoff \& Lardy, 1984), to reverse the carrier system and cause $\mathrm{Ca}^{2+}$ influx which in turn stimulates the sperm acrosome reaction, when the sperm intracellular $\mathrm{Na}^{+}$values have risen to a critical value (Hyne, 1984). The data suggest that when guinea-pig spermatozoa are capacitated 
by incubation in Medium MCM-PL, the ATP-dependent biochemical event is essentially complete within $1 \mathrm{~h}$ of incubation and sperm capacitation is then not inhibited by the addition of 2-deoxy-Dglucose. Direct evidence for the phosphorylation of an endogenous receptor during the acrosome reaction must await the development of a procedure to effectively label the sperm intracellular phosphate pools with a radiochemical marker.

We thank Dr A. Lopata and Ms D. Gook for their helpful comments. This study was supported by a N.H. \& M.R.C. (Australia) grant to R.V.H. and A. Lopata.

\section{References}

Babcock, D.F., First, N.L. \& Lardy, H.A. (1975) Transport mechanism for succinate and phosphate localized in the plasma membrane of bovine spermatozoa. J. biol. Chem. 250, 6488-6495.

Barros, C. (1974) Capacitation of mammalian spermatozoa. In Physiology and Genetics of Reproduction, Part B, pp. 3-24. Eds E. M. Coutinho \& F. Fuchs. Plenum Press, New York.

Bavister, B.D. (1981) Substitution of a synthetic polymer for protein in a mammalian gamete culture system. $J$. exp. Zool. 217, 45-51.

Bearer, E.L. \& Friend, D.S. (1982) Modifications of anionic-lipid domains preceding membrane fusion in guinea pig sperm. J. Cell Biol. 92, 604-615.

Bedford, J.M. (1983) Significance of the need for sperm capacitation before fertilization in eutherian mammals. Biol. Reprod. 28, 108-120.

Brandt, H. \& Hoskins, D.D. (1980) An AMP-dependent phosphorylated motility protein in bovine epididymal sperm. J. biol. Chem. 255, 982-987.

Davis, B.K. (1976) Influence of serum albumin on the fertilizing ability in vitro of rat spermatozoa. Proc. Soc. exp. Biol. Med. 151, 240-243.

Dravland, E. \& Meizel, S. (1981) Stimulation of hamster sperm capacitation and acrosome reaction in vitro by glucose and lactate and inhibition by the glycolytic inhibitor $\alpha$-chlorohydrin. Gamete Res. 4, 515-523.

Enyedi, A., Farago, A., Sarkadi, B., Szasz, I. \& Gardos, G. (1983) Cyclic AMP-dependent protein kinase stimulates the formation of polyphosphoinositides in the plasma membranes of different blood cells. FEBS Letters 161, 158-162.

Fraser, L.R. \& Quinn, P.J. (1981) A glycolytic product is obligatory for initiation of the sperm acrosome reaction and whiplash motility required for fertilization in the mouse. J. Reprod. Fert. 61, 25-35.

Frenkel, G., Peterson, R.N. \& Freund, M. (1975) Oxidative and glycolytic metabolism of semen components by washed guinea pig spermatozoa. Fert. Steril. 26, 144-147.

Friend, D.S. (1982) Neomycin/peroxidase/gold labeling of the guinea pig sperm acrosomal membrane. J. Cell Biol. 95, 149, Abstr.

Garbers, D.L., Tubb, D.J. \& Hyne, R.V. (1982) A requirement of biocarbonate for $\mathrm{Ca}^{2+}$-induced elevations of cyclic AMP in guinea pig spermatozoa. $J$. biol. Chem. 257, 8980-8984.

Hammerstedt, R.H. (1973) An automated method for ATP analysis utilizing the luciferin-luciferase reaction. Analyt. Biochem. 52, 449455.

Hiipakka, R.A. \& Hammerstedt, R.H. (1978) 2-Deoxy- glucose transport and phosphorylation by bovine sperm. Biol. Reprod. 19, 368-379.

Hoppe, P.C. (1976) Glucose requirement for mouse sperm capacitation in vitro. Biol. Reprod. 15, 39-45.

Hoppe, P.C. \& Whitten, W.K. (1974) An albumin requirement for fertilization of mouse eggs in vitro. $J$. Reprod. Fert. 39, 433-436.

Hoshi, K., Saito, A., Suzuki, M., Hayashi, K. \& Yanagimachi, R. (1982) Effects of substrates on penetration of human spermatozoa into the zona pellucida of human eggs and the zona-free hamster eggs. Jap. J. Fert. Steril. 27, 439-444.

Hyne, R.V. (1984) A bicarbonate and calcium dependent induction of rapid guinea-pig sperm acrosome reactions by monovalent ionophores. Biol. Reprod. 31, $312-323$

Hyne, R.V. \& Garbers, D.L. (1979a) Regulation of guinea pig sperm adenylate cyclase by calcium. Biol. Reprod. 21, 1135-1142.

Hyne, R.V. \& Garbers, D.L. (1979b) Calcium dependent increase in adenosine $3^{\prime}, 5^{\prime}$-monophosphate and induction of the acrosome reaction in guinea pig spermatozoa. Proc. natn. Acad. Sci. U.S.A. 76, 56995703.

Hyne, R.V. \& Garbers, D.L. (1981) Requirement of serum factors for capacitation and the acrosome reaction of guinea pig spermatozoa in buffered medium below pH 7.8. Biol. Reprod. 24, 257-266.

Hyne, R.V. \& Garbers, D.L. (1982) Inhibition of the guinea-pig sperm acrosome fraction by a low molecular weight factor(s) in epididymal fluid and serum. $J$. Reprod. Fert. 64, 151-157.

Hyne, R.V., Higginson, R.E., Kohlman, D. \& Lopata, A. (1984) Sodium requirement for capacitation and membrane fusion during the guinea-pig sperm acrosome reaction. J. Reprod. Fert. 70, 83-94.

Lopata, A., McMaster, R., McBain, J.C. \& Johnston, W.I.H. (1978) In-vitro fertilization of preovulatory human eggs. J. Reprod. Fert. 52, 339-342.

Lui, C.W., Cornett, L.E. \& Meizel, S. (1977) Identification of the bovine follicular fluid protein involved in the in vitro induction of the hamster sperm acrosome reaction. Biol. Reprod. 17, 34-41.

Mahi, C.A. \& Yanagimachi, R. (1976) Maturation and sperm penetration of canine ovarian oocytes in vitro. J. exp. Zool. 196, 189-195.

Mahi, C.A. \& Yanagimachi, R. (1978) Capacitation, acrosome reaction and egg penetration by canine spermatozoa in a simple defined medium. Gamete Res. 1, 101-109.

Mrnsy, R.J., Waxman, L. \& Meizel, S. (1979) Taurine 
maintains and stimulates motility of hamster sperm during capacitation in vitro. J. exp. Zool. 210, 123128.

Mujica, A. \& Valdes-Ruiz, M.A. (1983) On the role of glucose in capacitation and acrosomal reaction of guinea pig sperm. Gamete Res. 8, 335-344.

Niwa, K. \& Chang, M.C. (1975) Requirement of capacitation for sperm penetration of zona-free rat eggs. J. Reprod. Fert. 44, 305-308.

Oliphant, G. (1976) Removal of sperm bound seminal plasma components as a prerequisite to induction of the rabbit acrosome reaction. Fert. Steril. 27, 28-38.

Oliphant, G. \& Singhas, C.A. (1979) Iodination of rabbit sperm plasma membrane: relationship of specific surface proteins to epididymal function and sperm capacitation. Biol. Reprod. 21, 937-944.

O'Rand, M.G. (1979) Changes in sperm surface properties correlated with capacitation. In The Spermatozoon: Maturation, Motility, Surface Properties and Comparative Aspects, pp. 195-204. Eds D. W. Fawcett \& J. M. Bedford. Urban and Schwarzenberg, Baltimore.

Perreault, S.D. \& Rogers, B.J. (1981) Effect of various sugars on the time course of human spermatozoal capacitation in vitro. J. Androl. 2, 22, Abstr.

Quinn, P., Stanger, J.D. \& Whittingham, D.G. (1982) Effect of albumin on fertilization of mouse ova in vitro. Gamete Res. 6, 305-313.

Reeves, J.P. \& Sutko, J.L. (1983) Competitive interactions of sodium and calcium with the sodium calcium exchange system of cardiac sarcolemmal vesicles. J. biol. Chem. 258, 3178-3182.

Rogers, B.J. (1978) Mammalian sperm capacitation and fertilization in vitro: a critique of methodology. Gamete Res. 1, 165-223.

Rogers, B.J. \& Yanagimachi, R. (1975) Retardation of guinea pig sperm acrosome reaction by glucose: the possible importance of pyruvate and lactate metabolism in capacitation and the acrosome reaction. Biol. Reprod. 13, 568-575.

Rogers, B.J., Ueno, M. \& Yanagimachi, R. (1977) Inhibition of hamster sperm acrosome reaction and fertilization by oligomycin, antimycin $A$ and rotenone. J. exp. Zool. 199, 129-135.

Rogers, B.J., Chang, L. \& Yanagimachi, R. (1979)
Glucose effect on respiration: possible mechanism for capacitation in guinea pig spermatozoa. J. exp. Zool. 207, 107-112.

Rufo, G.A., Jr, Schoff, P.K. \& Lardy, H.A. (1984) Regulation of calcium content in bovine spermatozoa. J. biol. Chem. 259, 2547-2552.

Saling, P.M. \& Bedford, J.M. (1981) Absence of species specificity for mammalian sperm capacitation in vivo. J. Reprod. Fert. 63, 119-123.

Santos-Sacchi, J. \& Gordon, M. (1982) The effect of ATP depletion upon the acrosome reaction in guinea-pig sperm. J. Androl. 3, 108-112.

Stanley, P.E. \& Williams, S.G. (1969) Use of the liquid scintillation spectrometer for determining adenosine triphosphate by the luciferase enzyme. Analyt. Biochem. 29, 381-392.

Suter, D., Chow, P.Y.W. \& Martin, I.C.A. (1979) Maintenance of motility in human spermatozoa by energy derived through oxidative phosphorylation and addition of albumin. Biol. Reprod. 20, 505-510.

Tsunoda, Y. \& Chang, M.C. (1975) In-vitro fertilization of rat and mouse eggs by ejaculated sperm and the effect of energy sources on in-vitro fertilization of rat eggs. J. exp. Zool. 193, 79-86.

Wakelam, M.J.O. (1983) Inositol phospholipid metabolism and myoblast fusion. Biochem. J. 214, 77-82.

Webb, J.L. (1966) Analogs of enzyme reaction components: hexokinases. In Enzyme and Metabolic Inhibitors, Vol. 2, pp. 376-405. Academic Press, New York.

Weigensberg, A.M. \& Blostein, R. (1983) Energy depletion retards the loss of membrane transport during reticulocyte maturation. Proc. natn. Acad. Sci. U.S.A. 80, 4978-4982.

Yanagimachi, R. (1972) Fertilization of guinea pig eggs in vitro. Anat. Rec. 174, 9-20.

Yanagimachi, R. \& Usui, N. (1974) Calcium dependence of the acrosome reaction and activation of guinea pig spermatozoa. Expl Cell Res. 89, 161-174.

Yanagimachi, R., Yanagimachi, H. \& Rogers, B.J. (1976) The use of zona-free animal ova as a test-system for the assessment of the fertilizing capacity of human spermatozoa. Biol. Reprod. 15, 471-476.

Received 10 March 1984 